Makgatho et al., Afr J Tradit Complement Altern Med., (2017) 14 (5): 181-187

https://doi.org/10.21010/ajtcam.v14i5.21

\title{
EVALUATION OF THE ANTI-MYCOBACTERIAL, ANTI-OXIDATIVE AND ANTI-PROLIFERATIVE ACTIVITIES OF RUBIA CORDIFOLIA ETHANOLIC LEAF EXTRACT SUB-FRACTIONS IN HUMAN LYMPHOCYTES AND NEUTROPHILS
}

\author{
Makgatho, $\mathrm{ME}^{1^{*}}$; Nxumalo, $\mathrm{W}^{2}$; Ndaba, $\mathrm{E}^{1}$; Masilo, $\mathrm{C}^{1}$; Tsindane, $\mathrm{F}^{2}$; Sedibane, $\mathrm{Ml}^{1}$ \\ ${ }^{1}$ Department of Pathology and Medical Sciences, Faculty of Health Sciences. ${ }^{2}$ Department of Chemistry, \\ University of Limpopo, Private Bag X1106 Sovenga 0727, South Africa.
}

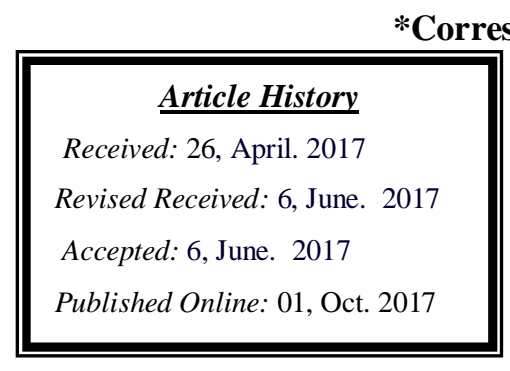

Abstract

Background. Rubia cordifolia has been used to treat various diseases and exhibits antimicrobial, anti-inflammatory, analgesic and antidiarrheal activities. The plant has not been investigated for its anti-mycobacterial activity against virulent tuberculosis strains as well as cytotoxic and anti-oxidant activities in mononuclear cells and neutrophils.

Methods. Ethanolic and dichloromethane leaf extract fractions of Rubia cordifolia $(0.2-125 \mu \mathrm{g} / \mathrm{ml})$ were screened for anti-mycobacterial activity using a fluorescent microplate assay. The anti-oxidant activity of the fractions was tested using the radical scavenging assay, while their cytotoxicity to lymphocytes was measured using the WST- 8 assay. Reactive oxygen species production by neutrophils exposed to fractions was tested using Cell Meter ${ }^{\mathrm{TM}}$ Fluorimetric ROS Assay kit.

Results. The ethanolic leaf fractions exhibited overall superior anti-mycobacterial activity than the dichloromethane group and were further screened for anti-oxidant and cytotoxic activities. Ethanolic sub-fractions K2F-3.2, K2F-3.3 and K2F-3.4 showed significant antioxidant activities at concentration of $50 \mu \mathrm{g} / \mathrm{ml}$ to $200 \mu \mathrm{g} / \mathrm{ml}$ and higher in both the cell free-based radical scavenging activity and total reactive oxygen species production assays. For lymphocytes, the test agents showed anti-proliferative activity at $25 \mu \mathrm{g} / \mathrm{ml}$ to $200 \mu \mathrm{g} / \mathrm{ml}$ for sub-fraction $\mathrm{K} 2 \mathrm{~F}-3.3 \mathrm{~B}$ and $50 \mu \mathrm{g} / \mathrm{ml}$ to 200 $\mu \mathrm{g} / \mathrm{ml}$ for agents $\mathrm{K} 2 \mathrm{~F}-3.2$ and $\mathrm{K} 2 \mathrm{~F}-3.4$.

Conclusion. The current study is the first to record the in vitro anti-mycobacterial, anti-oxidant and cytotoxic activities of Rubia cordifolia plant leaf extract sub-fractions using the given experimental setups and further research activities to identify the bioactive components are to be pursued.

Key words: Rubia cordifolia, DPPH, Mycobacteria, cell proliferation, antioxidant activity, ROS.

\section{Introduction}

Tuberculosis (TB), compared to HIV/AIDS, is the second highest communicable disease that leads to high mortality rates worldwide due to Mycobacterium tuberculosis (WHO, 2014; WHO, 2015). The disease is expected to surge in the future due to various forms of multidrug drug resistance (MDR): multidrug resistant (MDR), extremely drug resistant and (XDR) and totally drug resistant (TDR) tuberculosis and co-infection with human immunodeficiency virus (HIV) (Mistry et al., 2012; Abubakar et al., 2013 and WHO, 2015). The South African TB/HIV/AIDS coinfections are extremely high with $73 \%$ of TB patients co-infected with HIV (Soul City Research Unit, 2015). This situation calls for an emergence prioritisation of development of new and novel agents for TB treatment and management.

There is a resurgence of research activities to explore the use of medicinal plant bio-products as potential antimycobacterial agents in South Africa (Lall and Meyer, 1999; Bapela et al., 2006; Eldeen and Van Staden, 2008; Green et al., 2010; Labischagné et al., 2012; Aro et al., 2016 and Komape et al., 2017). Plant extracts with high anti-oxidant capacity have been presented as exhibiting bactericidal activity against Mycobacterium tuberculosis (Newton et al., 2000; Okunade et al., 2004; Pauli et al., 2005 and Gouveia-Figueira et al., 2014; Magadula et al., 2012). Tuberculosis as an infection present an inflammatory response in the lungs whereby cellular mediators are released causing oxidative stress (Sommer, 2005). The most vital of the mediators are reactive oxygen species (ROS) and hydrogen peroxide $\left(\mathrm{H}_{2} \mathrm{O}_{2}\right)$. Excess production of these oxidants leads to harmful inflammatory reactions in the lungs (caseous necrosis) and antioxidant material that scavenges and eliminate ROS may be important in preventing or minimizing oxidative- 
related damage in clinical conditions like tuberculosis (Constantino et al., 1992; Reljic et al., 2010; Bernardes et al., 2014 and Dzoyem and Ellof, 2015).

Other studies have focused on the repurposing of compounds that have anti-inflammatory activity as they present an alternative to combating increased antimicrobial drug resistance (Kulkarni and Deshpande, 2016; Maitra et al., 2016 and Prasad et al., 2016). Plant products or chemical entities that exhibits antimicrobial and anti-inflammatory activities should be considered for prospects in combatting Mycobacterial tuberculosis infection (Trevisan et al., 2016). Rubia cordifolia Linn. (Rubiaceae) is also known by other common names like Manjistha and Majith depending on the geographical location. It is distributed in tropical Africa, India, Japan and Indonesia (Tailor et al., 2010; Deshkar et al., 2008). The various parts of the plant have been shown to exhibit a myriad of ethno-medicinal applications like: antidiarrheal, anti-inflammatory, antimicrobial, antipyretic and analgesic activities (Kasture et.al 2000; Joharapurkar et.al., 2003; Devi Priya and Siril., 2014; Verma et.al., 2016; Gong et.al., 2017). Medicinal plants and their bioactive compounds can serve as an alternative choice for resistant Tuberculosis treatment, provided the agents are less toxic and anti-inflammatory because Tuberculosis is a highly inflammatory phenomenon that damages lungs (Semenya and Maroyi, 2013; Nyambuya et al., 2017; Komape et al., 2017).

To this end, the anti-mycobacterial activity of crude ethanolic and dichloromethane (DCM) leaf extracts of Rubia cordifolia were investigated for anti-mycobacterial activity in vitro. The crude extracts that exhibited the most potent activity were further fractionated to screen for possible: anti-mycobacterial, antioxidant and anti-proliferative activities.

\section{Materials and Methods}

Unless otherwise indicated, all chemicals and reagents were obtained from Sigma-Aldrich (Johannesburg, South Africa).

\section{Plant collection and preparation of leaf extracts and sub-fractions}

Rubia cordifolia plants were collected from traditional healers in Tzaneen (Mopani District, Limpopo Province, South Africa) and a voucher specimen of the plant was deposited in the University of Limpopo Herbarium under the accession number 11208 . Ethanol $(100 \mathrm{ml})$ was added to $5 \mathrm{~g}$ of dried powder from plant leafs in a $500 \mathrm{ml}$ volumetric flask. The resultant mixture was stirred at room temperature for $24 \mathrm{~h}$. The mixture was filtered to remove undissolved material and then washed with $2 \times 10 \mathrm{ml}$ Ethanol. The solvent was removed in a rotary evaporator to give $2.233 \mathrm{~g}$ of crude extract. The crude extract was then subjected to preparative thin layer chromatography (prep-TLC), eluting with methanol-DCM (1:19) to give four fractions.

\section{Green fluorescent protein microplate assay (GFPMA) for anti-mycobacterial screening}

This broth micro dilution technique (Collins et. al., 1998) allows an array of drug concentrations to be screened on a single 96-well microtitre plate in order to determine minimum inhibitory concentration (MIC). Briefly, culture (10 ml) of a mutant Mycobacterium tuberculosis (H37RVMA) strain (Ioerger et.al., 2010) constitutively expressing recombinant green fluorescent protein (GFP) is grown to an $\mathrm{OD}_{600}$ of 0.6-0.7 and diluted 1:100 in GAST/Fe medium. To the wells of the test plate was added $100 \mu \mathrm{l}$ of culture suspension and two-fold dilutions of the test agents $(0.2-125 \mu \mathrm{g} / \mathrm{ml}$, final concentration) in triplicates to a final volume of $200 \mu \mathrm{l}$. Control wells contained untreated bacterial culture suspensions (positive control) and medium only (background control). The plates were incubated at $37^{\circ} \mathrm{C}$ and fluorescence measured at day 7 post incubation using a Flurostar Optima microplate reader (BMG Labtech, Thermofisher Scientific, USA) with excitation at $484 \mathrm{~nm}$ and emission at $508 \mathrm{~nm}$. Percent inhibition was calculated as 1- (test well FU/FU of background wells X 100). MIC was expressed as the lowest drug concentration inhibiting $90 \%$ and $99 \%$ of bacterial growth.

\section{Determination of antioxidant activity of ethanolic sub-fractions by DPPH method}

The radical scavenging activity of the extract was determined by the method described by Krings and Berger (Krings and Berger, 2001). To $1 \mathrm{ml}$ of $0.1 \mathrm{mM}$ solution of DPPH in ethanol, was added $3 \mathrm{ml}$ of test agents (6$200 \mu \mathrm{g} / \mathrm{ml}$ ) in distilled water and kept for 30 minutes. The colour change of the reaction mixture was then read at 517 $\mathrm{nm}$ in a plate reader DXT 800 multimode plate reader (Beckman Coulter, Johannesburg, South Africa).

\section{Preparation of PBMCs from human peripheral blood}

PBMCs were obtained by collecting venous blood $(8 \mathrm{ml})$ into specialised BD Vacutainer ${ }^{\circledR}$ CPT $^{\mathrm{TM}}$ tubes according to the manufacturer's instruction (Beckton Dickinson, Johannesburg, South Africa). Ethical approval to draw blood from donors was obtained from the University of Limpopo Research and Ethics Committee (TREC/117/2016:UG). 
Purified neutrophils were prepared from heparinized venous blood of healthy adult human volunteers and were separated from mononuclear leukocytes by centrifugation on Histopague-1077 at $300 \mathrm{~g}$ for $25 \mathrm{~min}$ at $4^{0} \mathrm{C}$. After removal of the plasma and mononuclear cell layers, $5 \mathrm{ml}$ of Verasylase was added to the residual red blood cell pellet that contained neutrophils and incubated for $15 \mathrm{~min}$ to lyse the erythrocytes. After incubation, the suspension was resuspended in abundant HBSS buffer and centrifuged at $160 \mathrm{~g}$ for $10 \mathrm{~min}$. The supernatant was aspirated and the pellet washed twice in HBSS at $110 \mathrm{~g}$ for $10 \mathrm{~min}$. Neutrophils of high purity (>90\%) were prepared at $2 \times 10^{7}$ cells $/ \mathrm{ml}$ and held on ice before assaying for total ROS production.

\section{Detection of total ROS production by ethanolic sub-fractions on purified neutrophils}

Cells were incubated for $5 \mathrm{~min}$ with or without test material $(6-200 \mu \mathrm{g} / \mathrm{ml})$ and ROS production detected using a Cell Meter ${ }^{\mathrm{TM}}$ Fluorimetric ROS Assay Kit according to the manufacturer's instruction (Cayman Chemical, Johannesburg, South Africa).

\section{Determination of growth inhibitory effects of ethanolic sub-fractions on human lymphocytes}

After incubating the PBMCs $\left(2 \times 10^{6} \mathrm{cells} / \mathrm{ml}\right)$ for 72 hours with or without plant isolates $(6-200 \mu \mathrm{g} / \mathrm{ml})$, proliferative activity was determined using the WST-8 assay following the manufacturer's instructions (Cayman Chemicals, Johannesburg, South Africa).

\section{Data analysis}

Numerical data of experiments (repeats of 3-4 experiments in triplicates) was analysed using Microsoft Excel 2009 Version for Windows. Results are expressed as mean \pm SD (Standard deviation). A $\mathrm{p} \leq 0.05$ considered to be significant.

\section{Results}

Anti-mycobacterial activity of Rubia cordifolia leaves were tested on DCM and ethanolic extracts against $\mathrm{H}_{37} \mathrm{Rv}$ strain of Mycobacterium tuberculosis using the green fluorescence protein microplate assay (GFPMA). The ethanolic crude extract (K2F-3) was less active than the DCM (K2F-1) crude extract, with MIC 90 of 57.3 and 44.5 $\mu \mathrm{g} / \mathrm{ml}$ respectively as shown in Table 1 and Table 2 respectively. Fractionation of the crude extracts by preparative chromatography, eluting with 5\% methanol-DCM afforded four sub-fractions from each crude. The sub-fractions from the ethanol crude demonstrated better activity compared to those obtained from the DCM crude (Table 1 and 2) and were further screened for anti-oxidant activity.

Table 1: Minimum inhibitory concentrations ( $\mathrm{MIC}_{90}$ and $\mathrm{MIC}_{99}$ ) of ethanolic leaf extracts of Rubia cordifolia against the H37Rv strain of Mycobacterium tuberculosis.

\begin{tabular}{|l|l|l|}
\hline Sample name & MIC $_{90}(\mu \mathrm{g} / \mathrm{ml})$ & MIC $_{99}(\mu \mathrm{g} / \mathrm{ml})$ \\
\hline K2F-3 (Ethanol crude) & 57.3 & 63.7 \\
\hline K2F-3.1 & 35.5 & 41.2 \\
\hline K2F-3.2 & 26.2 & 28.7 \\
\hline K2F-3.3 & 38.8 & 45.8 \\
\hline K2F-3.4 & 39.4 & 41 \\
\hline
\end{tabular}

Table 2: Minimum inhibitory concentrations ( $\mathrm{MIC}_{90}$ and $\mathrm{MIC}_{99}$ ) of DCM leaf extracts of Rubia cordifolia against the H37Rv strain of Mycobacterium tuberculosis.

\begin{tabular}{|l|l|l|}
\hline Sample name & MIC $_{90}(\mu \mathrm{g} / \mathrm{ml})$ & MIC $_{99}(\mu \mathrm{g} / \mathrm{ml})$ \\
\hline K2F-1 (DCM crude) & 44.5 & 57 \\
\hline K2F-1.1 & 52.8 & 57.8 \\
\hline K2F-1.2 & 71.6 & 82.7 \\
\hline K2F-1.3 & 40.2 & 46.9 \\
\hline K2F-1.4 & 27.5 & 30.2 \\
\hline
\end{tabular}

The DPPH radical scavenging activity measures the antioxidant potential of the ethanolic sub-fractions of Rubia cordifolia as shown in Figure 1. The results show that sub-fractions K2F-3.2 B, KF-3.3B and K2F-3.4B exhibits significant DPPH activity (more than $60 \%$ ) from $50 \mu \mathrm{g} / \mathrm{ml}$ to $200 \mu \mathrm{g} / \mathrm{ml}$ (p < 0.05) with sub-fraction K2F-3.1B showing no activity at the concentrations tested $(\mathrm{p}>0.05)$. A $\mathrm{p}<0.05$ value also indicates a comparable and significant DPPH activity by the ethanolic crude extract as is Vitamin $B_{12}$ which acted as the positive control in this instance. The three sub-fractions exhibiting significant DPPH activity were then further screened for total ROS production and cytotoxic activity in isolated neutrophils and lymphocytes. 


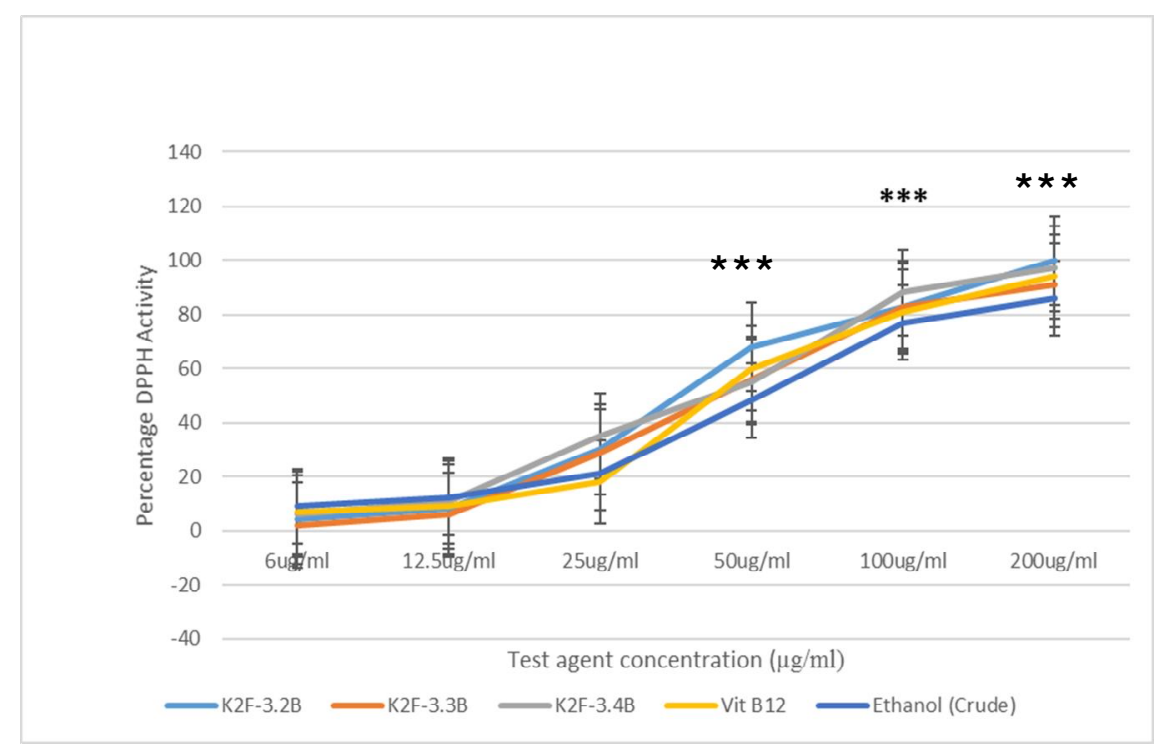

Figure 1: The free radical scavenging activity of ethanolic leaf extract sub-fractions of Rubia cordifolia as determined by the DPPH assay. Results are expressed as mean percentage DPPH activity by the test agents $(6-200 \mu \mathrm{g} / \mathrm{ml}) \mathrm{plus}$ SEM of four different experiments conducted in triplicates. *The result is statistically significant.

Results for the production of total reactive oxygen species (ROS) by human neutrophils using the Cell Meter $^{\mathrm{TM}}$ Fluorimetric ROS Assay Kit are shown in Figure 2. There is an indication of a dose-dependent increase in total ROS production by the three sub-fractions, with sub-fraction K2F-3.3B exhibiting significant activity from 25 $\mu \mathrm{g} / \mathrm{ml}$ to $200 \mu \mathrm{g} / \mathrm{ml}(\mathrm{p}<0.05)$ while sub-fractions are active from $50 \mu \mathrm{g} / \mathrm{ml}$ to $200 \mu \mathrm{g} / \mathrm{ml}(\mathrm{p}<0.05)$.

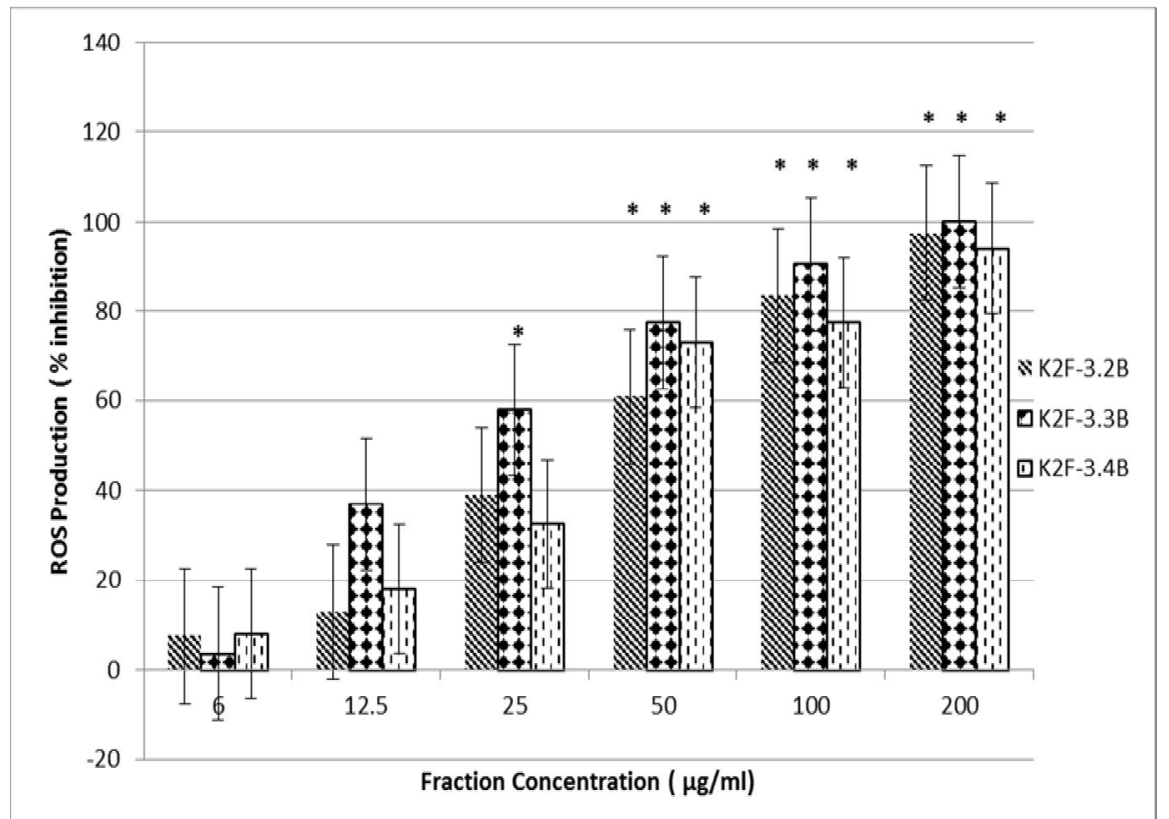

Figure 2: Percentage inhibition of ROS production by ethanolic leaf extract sub-fractions of Rubia cordifolia in neutrophils in vitro. Results are expressed as the mean percentage of inhibition of ROS production by the test agents (6$200 \mu \mathrm{g} / \mathrm{ml}$ ) plus SEM of four different experiments conducted in triplicates. *The result is statistically significant.

The cytotoxic activity of the three ethanolic sub-fractions of $R$. cordifolia against peripheral blood mononuclear cells (lymphocytes) using the WST-8 assay are indicated in Figure 3. Ethanolic fraction K2F-3.3B did show a significant inhibition of lymphocyte proliferation from $25 \mu \mathrm{g} / \mathrm{ml}$ and higher $(\mathrm{p}<0.05)$ while the other two agents, K2F-3.2B and K2F-3.4 exhibited observable cytotoxic activity from $50 \mu \mathrm{g} / \mathrm{ml}$ and higher $(\mathrm{p}<0.05)$ as shown in the figure. 


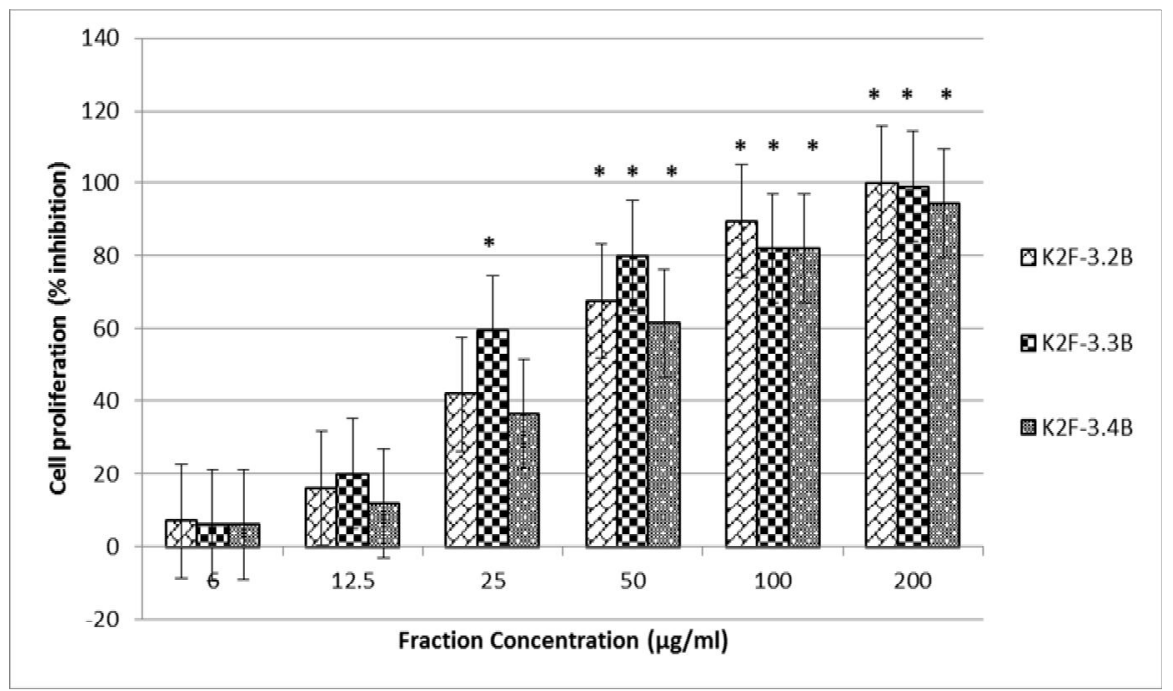

Figure 3: Percentage cell proliferation inhibition by ethanolic leaf extract sub-fractions of Rubia cordifolia on lymphocytes in vitro. Results are expressed as the mean percentage inhibition of cell proliferation by test agents (6-200 $\mu \mathrm{g} / \mathrm{ml}$ ) plus SEM of four different experiments conducted in triplicates. *The result is statistically significant.

\section{Discussion and Conclusion}

The current study present results of ethanolic leaf extract sub-fractions of Rubia cordifolia showing superior antimycobacterial activity to that of the DCM sub-fractions at $\mathrm{IC}_{90}$ values of less than $50 \mu \mathrm{g} / \mathrm{ml}$ compared to that of the $\mathrm{DCM}$ test material (highest $\mathrm{IC}_{90}$ value of $72 \mu \mathrm{g} / \mathrm{ml}$ ). The concentration range attained for in vitro anti-mycobacterial activity in this study is comparable or lower to other studies recently reported for different plant and mycobacterial species as well as experimental procedures employed (Bernadres et.al., 2016; Nguta et.al., 2016; Trevisan et.al, 2016; Komape etal., 2017; Nyambuya et.al., 2017).

The other part of the investigations focused on screening the antioxidant and anti-proliferative activities of the ethanolic leaf extracts sub-fractions. Pro-inflammatory mediators play a significant part in protective immunity in tuberculosis and their maintenance and strict control is important to avoid immunopathic cases due to excessive and inappropriate production (Lyadova and Panteleev, 2015; Amaral et.al., 2016; Piñeros et.al., 2017). Only three of the sub-fractions: KF2-3.2B, K2F-3.3B and K2F-3.4 exhibited dose-dependent antioxidant and anti-proliferative activities that attained prominence from $50 \mu \mathrm{g} / \mathrm{ml}$ to $200 \mu \mathrm{g} / \mathrm{ml}$. There is apparently paucity of literature reports on the screening of leafs extracts of Rubia cordifolia in laboratory experimental models used in the current study.

Various studies conducted to investigate the anti-inflammatory and antioxidant potential of Rubia cordifolia used roots and stems as screening material (Patil et.al., 2006; Basu and Hazra, 2006; Karodi et.al., 2009; Deoda et al., 2011). The laboratory experimental systems used for anti-inflammatory activity are ex vixo and mostly animal models (Lopez-Exposito et.al., 2011; Gong et.al, 2017). The present study affirms that leaf extract sub-fractions of Rubia cordifolia does exhibit cytotoxic and antioxidant activities at acceptable concentrations even when different laboratory experimental models are used. In this case we used isolated human peripheral blood mononuclear cells (lymphocytes) and neutrophils. The anti-proliferative and antioxidant properties of leafs of Rubia cordifolia are consistent with them containing various chemical derivatives of anthraquinones (Devi Priya and Siril, 2014; Sreenu et.al., 2014; Maharjan and Nampoothiri, 2015; Panigrahi et.al., 2016; Verma et.al., 2016).

The anti-mycobacterial, cytotoxic and antioxidant activities of three ethanolic leaf extract sub-fractions of Rubia cordifolia are still preliminary and further laboratory work is warranted to: isolate their bioactive elements, elucidate their apoptotic pathways and screen various drug combination schema in in vitro and animal models of experimental Tuberculosis.

\section{Acknowledgements}

The project was funded by the University of Limpopo and National Research Foundation (NRF) grant number: TTK1205280912.

Ethical consideration: The research proposal and laboratory work were approved by the University of Limpopo Research and Ethics Committee with approval certificate number: TREC/117/2016:UG.

Conflict of Interest: Authors declare that there is no conflict of interest. 


\section{References}

1. Abubakar, I., Zignol, M., Falzon, D., Raviglione, M., Ditiu, L., Adetifa, I., Ford, N., Cox, H., Lawn, S.D., Marais, B.J., McHugh, T.D., Mwaba, P., Bates, M., Lipman, M., Zijenah, L., Logan, S., mCnerny, R., Sumla, A., Sarda, K., Nahid, P., Hoelcsher, P., Pletschette, M., Memish, Z.A., Kim, P., Hafner, R., Cole, S., Migliori, G.A., Mauerer, M.and Zumla, A. (2013). Drug-resistant tuberculosis: time for visionary political leadership. Lancet Infect Dis. 13: 529-539.

2. Amaral, E.P., Lasunskaia, E.B, and D'Império-Lima, M.R. (2016). Innate immunity in tuberculosis: how the sensing of mycobacteria and tissue damage modulates macrophage death. Microb Infect. 18: 11-20.

3. Aro, A.O., Dzoyem, J.P., Eloff, J.N. and Mc Gaw, L.J. (2016). Extracts of six Rubuceae species combined with rifampicin have good in vitro synergistic antimycobacterial activity and good anti-inflammatory and antioxidant activities. BMC Complement Altern Med. 16: 385-392.

4. Bapela, N.B., Lall, N., Fourie, F.B., Franzblau, S.G. and Van Rensburg, CEJ. (2006). Activity of 7-mrthyljuglone in combination with antituberculous drugs against Mycobactrium tuberculosis. Phytomed. 13: 630-635.

5. Basu, S and Hazra, B. (2006). Evaluation of nitric oxide scavenging activity, in vitro and ex vivo, of selected medicinal plants traditionally used in inflammatory diseases. Phytother. Res. 20: 896-900.

6. Bernardes, N.R., Heggdorne-Aeaujo, M., Borges, I.F.J.C., Almeida, F.M., Amaral, E.P., Lasunskiai, E.B., Muzitano, M.F and Oliveira, D.B. (2014). Nitric oxide production, inhibitory, antioxidant and antimycobacterial activities of the fruits extract and flavonoid content of Schinus terebinthifolius. Rev Bras Farmacogn. 24: 644-650.

7. Constantino, L., Albasini, A., Rastelli, G. and Benvenuti, S. (1992). Activity of polyphenolic crude extracts as scavengers for superoxide radicals and inhibitors of xanthine oxidase. Planta Med. 58: 342-344.

8. Deoda, R.S., Kumar, D., Kadam, V.P., Yadav, K.N., Bhujbal, S.S and Patil, M.J. (2011). Pharmacognostic and biological studies of the roots of Rubia cordifolia Linn. Int. J. Drug. Dev. Res. 3: 148-158.

9. Deshkar, N., Tillo, N.D., Shrikant, T and Vipichandra, P. (2008). A comprehensive review of Rubia cordifolia Linn. Pharmacog. Rev. 2: 124-134.

10. Devi Priya, M and Siril, E.A. (2014). Traditional and modern use of Indian Madder (Rubia cordifolia L.): An Overview. Int. J. Pharm. Sci. Rev. Res. 25: 154-164.

11. Dzoyem, J.P and Eloff, J.N. (2015). Anti-inflammatory, antyicholinesterase and antioxidant activity of leaf extracts of twelve plants used traditionally to alleviate pain and inflammation in South Africa. J Ethonopharmacol. 160: $194-201$.

12. Eldeen, I.M.S. and Van Staden, I. (2008). Cyclooxygenase inhibition and antimycobaterial effects of extracts from Sudanese medicinal plants. SAJB. 74: 225-229.

13. Gong, X., Sun, Y., Chen, W., Guo, Xia., Guan., J., Li D and Du G. (2017). Anti-diarrheal and anti-inflammatory activities of aqueous extract of the aerial part of Rubia cordifolia. BMC Altern. Med. 17: 20-37.

14. Gouveia-Figueira, S.C., Gouveia, C.A., Carvalho, M.J., Rodrigues, A.I., Nording, M.L. and Castilho, M.J. (2014). Antioxidant capacity, cytotoxicity and antimycobacterial activity of Madeira Archipelago endemic Helichrysum dietary and medicinal plants. 3: 713-729.

15. Green, E., Samie, A., Obi, C.L., Bessong, P. and Ndip, R.N. (2010). Inibitory properties of selected South African medicinal plants against Mycobacterium tuberculosis. J Ethopharmacol. 130: 151-157.

16. Joharapurkar, A.A., Zambad, S.P., Wanjari,M.M and Umathe, S.N. (2003). In vivo evaluation of antioxidant activityof alcoholic extract of Rubia cordifolia Linn. and its influence on ethanol-induced immunosuppression. Indian J. Pharmacol. 35: 232-236.

17. Karodi, R., Jadhav, M., Rub, R and Bafna, A. (2009). Evaluation of the wound healing activity of a crude extract of Rubia cordifolia L. (Indian madder) in mice. Int. J. Applied Res. Natl. Products. 2: 12-18.

18. Kasture, V.S., Deshmukh, V.K and Chopde, C.T. (2000). Anticonvualsant and behavioural actions of triterpene isolated from Rubia cordifolia Linn. Indian J. Exp. Biol. 38: 675-680.

19. Komape, N.P.M., Bagla, V.P., Kabongo-Kayoka, P and Masoko, P. (2017). Anti-mycobacterial potential and synergistic effects of combined crude extrects of selected medicinal plants used by Bapedi traditional healers to treat tuberculosis related symptoms in Limpopo Province, South Africa. BMC Altern. Med. 17: 124-134.

20. Krings, U. and Berger, R.G. (2001). Antioxidant activity of some roasted foods. Food Chem. 72: 223-229.

21. Kulkarni, R.A. and Deshpande, A.R. (2016) Anti-inflammatory and antioxidant effect of ginger in tuberculosis. J. Complement Intergrat. Med. 13: 201-206.

22. Labischagné, A., Hussein, A.A., Rodríguez, B. and Lall, M. (2012). Synergistic antimycobacterial actions of Knowltonia vesicatoria (L.F) Sims. Evid Based Complement Alternat Med. 2012: 808979.

23. Lall, N. and Meyer, J.J.M. (1999). In vitro inhibition of drug-resistant and drug-sensitive strains of Mycobacterium tuberculosis by ethnobotanically selected South African plants. J Ethnopharmacol. 66: 347-354.

24. Lópezo-Expósito, I., Castillo, A., Yang, N., Liang, B and Li, X. (2011). Chinese herbal extracts of Rubia cordifolia and Dianthus superbus supress IgE production and prevent peanut-induced anaphylaxis. Chinese Med. 6: 35-44.

25. Lyadova, I.V. and Panteleev, A.V. (2015). Th1 and Th2 cells in Tuberculosis: Protection, Pathology, and Biomarkers. Mediators Inflammation. http://dx.doi.org/10.1155/2015/854507. Accessed 2017 April 06.

26. Magadula, J.J., Otieno, J.N., Nondo, R.S., Kirimuhuzya, C., Kadukuli, E., Orodho, J.A and Okemo, P. (2012). Antimycobacterial and toxicity activities of some priority medicinal plants from Lake Victoria Basin, Tanzania. 2:125-131.

27. Maharjan, H.R and Nampoothiri, P.L. (2015). Evaluation of biological properties and clinical effectiveness of Aloe vera: A systematic review. J Tradit Complement Med. 5: 21-26. 
28. Maitra, A., Bates, S., Shaik, M., Evangelopoulos, D., Abubakar, I, McHugh, T.D., Lipman. and Khakta, S. (2016). Repurposing drugs for treatment of tuberculosis: a role of non-steroidal anti-inflammatory drugs. Br Med Bull. 118: $138-148$.

29. Mistry, N., Tolani, M. and Osrin, D. (2012). Drug-resistant tuberculosis in Mumbai, India: An agends for operations research. 1: 45-53.

30. Newton, S.M., Lau, C, and Wright, C.W. (2000). A review of antimycobacterial natural products. Phytotherapy Research. 14: 303-322.

31. Nguta, J.M., Appiah-Opong, R., Nyarko, A.K., Yeboah-Manu, D., Addo, P.G.A., Otchere, I, and Kissi-Twum, A. (2016). Antimycobacterial and cytotoxic activity of selected medicinal plant extracts. J Ethnopharmacol. 182: 10-15.

32. Nyambuya, T., Mautsa, R and Mukanganyama, S. (2017). Alkaloid extracts from Combretum zeyheri inhibit the growth of Mycobacterium smegmatis. BMC Altern. Med. 17: 124-134.

33. Okunade, A.L., Elvin-Lewin, M.P.F. and Lewis, W.H. (2004). Natural antimycobacterial metabolites: Current status. Phytochem. 65: 1017-1032.

34. Panigrahi, G.K., Yadav, A., Mandal, P., Tripathi, A and Das, M. (2016). Tox. Lett. 245: 15-23.

35. Patil, R.A., Jagdale, S.C and Kasture, S.B. (2006). Antihyperglycemic, antistress and noortropic activity of roots of Rubia cordifolia Linn. Indian J Exp Biol. 44: 987-992.

36. Pauli, G.F., Case, R.J., Inui, T., Wang, Y., Cho, S., Fischer, N.H. and Franzblau, S.G. (2005). New perspectives on natural products in TB drug research. Life Sci. 78: 485-494.

37. Piñeros, A.R., Campos, L.W., Fonseca, D.M., Bertolini, T.B., Gembre, A.F., Prado, R.Q., Alves-Filho, J.C., Ramos, S.G., Russo, M. and Bonato, V.L.D. (2017) M2 macrophages or IL-33 treatment attenuate ongoing Mycobacterium tuberculosis infection. Doi:10.1038/srep41240. Accessed 2017 April 06.

38. Prasad, K., Singh, M.B. and Ryan, H. (2016). Corticosteroids for managing tuberculosis meningitis. Cockrane Database Syst. Rev. 4: 1-64.

39. Reljic, R., Stylianou, E., Balu, S. and Ma, J.K. (2010). Cytokine interactions that determine the outcomes of mycobacterial infection of macrophages. Cytokine. 51: 42-46.

40. Sommer, C. (2005). Inflammation and healing. In: Mattison CP. Editor. Pathophysiology. Seventh ed. London: Lippincott and Wilkins; pp: 387-398.

41. Soul City Research Unit. (2015). Literature Review of TB in South Africa. Version 1, 2-89.

42. Sreenu, P., Samatha, T., Gandhi, N. and Naik, Azmeera. (2014). Phytochemical analysis of root, stem and leaf extracts of Rubia cordifolia L. An important medicinal plant. World J Pharm Pharmaceut Sci. 3: 826-838.

43. Semenya, S.S and Maroyi, A. (2013). Medicinal plants used for the treatment of Tuberculosis by Bapedi traditional healers in three districts of the Limpopo Province, South Africa. SAJB. 10: 316-323.

44. Tailor, C.S., Bahuguna, Y.M and Signh, V. (2010). Anti-inflammatory activity of ethanolic stem extracts of Rubia cordifolia Linn. in rats. Int J Res Ayurveda Pharm. 1: 126-130.

45. Trevisan, L.N.F., do Nascimento, K.F., Santos, J.A., Kassuta, C.A.L., Cardoso, C.A.L., Vieira, M., Moreira, F.M.G., Croda, J. and Formagio, A.S.N. (2016). Anti-inflammatory, antioxidant and anti-Mycobacterium tuberculosis activity of viridiflorol: The major constituent of Allophylus edulis (A. St.-Hill., Juss. \& Cambess.) Radlk. J Ethnopharmacol. 20: $510-515$.

46. Verma, A., Kumar, B., Alam, P., Singh, V. and Gupta, S.K. (2016). Rubia cordifolia - A review on pharmaconosy and phytochemistry. Int J Pharmaceut Sci Res. 7: 2720-2731.

47. World Health Organization. (2015). Multidrug resistant tuberculosis (MDR-TB), Update. Geneva. Switzerland.

48. World Health Organization. (2014). Global TB burden 2014. Geneva. Switzerland. 